\title{
A CRITICAL REVIEW OF POPULAR MULTI-CRITERIA DECISION MAKING METHODLOGIES
}

\author{
Yong B. Shin, Francis Marion University,yshin@fmarion.edu \\ Seungho.Lee,Ulsan College, shlee@uc.ac \\ Sun Gi Chun, Alabama State University, sungichun@alasu.edu \\ Dalsang Chung , Governors State University, dchung@govst.edu
}

\begin{abstract}
Analytic Hierarchy Process (AHP) is a powerful quantitative measurement method in the multi-criteria decision making (MCDM) area. It has been used in banks, manufacturing systems, organizational performance evaluation, and project selection. Despite this widespread usage, many studies argue that rank reversal phenomenon is unpreventable when any AHP method is applied. This paper presents that the rank reversal occurs in other popular MCDM approaches as well, such as Borda-Kendall (BK), Technique for Order Preference by Similarity to Ideal Solution (TOPSIS), and the simple additive weighting (SAW) approaches. For avoiding rank reversal phenomenon in decision matrices where such reversals should not take place, this paper attempts to illustrate that the proposed least common multiple (LCM) approach successfully addresses these rank reversal problems in most popular MCDM approaches in decision support systems area.
\end{abstract}

Keywords: Multiple Criteria Decision Making (MCDM), Analytic Hierarchy Process (AHP), Rank reversal, and Least Common Multiple (LCM) method

\section{INTRODUCTION}

Over the past three decades, the analytic hierarchy process (AHP) developed by Saaty [10] has become a very popular multiple criteria decision making (MCDM) technique. AHP has been applied to diverse fields of study such as software evaluation, manufacturing systems, organizational performance evaluation, customer requirement rating, and financial industries. However, for nearly the same duration, AHP has also been criticized for rank reversals when a decision alternative is added or dropped, first noted by Belton et al. [2].

In order to avoid rank reversal phenomenon in the AHP where such reversals should not take place, many other different mathematical approaches $[1,4,8,12]$ have been proposed. It is noticeable that none of these methods have resolved this problematic phenomenon and there are still on-going debates on how to avoid rank reversals.

Rank reversals are also found in many other popular MCDM approaches as well, such as Borda-Kendall [7] for ordinal preference measurements, Technique for Order Preference by Similarity to Ideal Solution (TOPSIS) [6], and the simple additive weighting (SAW) approach [9]. This paper proposes an alternative method that yields a reliable decision and the preservation of ranking of alternatives when a decision option is added or dropped. The purpose of this paper is to illustrate that the rank reversals occur in other MCDM approaches and present that the proposed approach successfully addresses these rank reversal problems of the most popular MCDM approaches in decision support systems area.

\section{RANK REVERSAL PHENOMENON IN AHP AND A PROPOSED LCM APPROACH}

\section{Rank reversal in the AHP}


Within a framework of AHP [10], a decision problem is decomposed into a hierarchy of the goal, criteria, subcriteria, and finally alternatives at the bottom of the hierarchy. The rating method using elements in Table 1 is carried out as follows: 1) the criteria are compared pairwise to derive their normalized weights which sum to one, 2) the alternatives also are compared pairwise with respect to each criterion to derive their relative local priorities, finally, 3) the local alternative priorities are aggregated with the criteria weights to produce the overall priorities for the alternatives in a decision matrix.

Table 1. The fundamental scale

\begin{tabular}{|l|l|}
\hline $\begin{array}{l}\text { Intensity of preference on } \\
\text { an absolute scale }\end{array}$ & Definition \\
\hline 1 & Equal preference \\
3 & Moderate preference of one over others \\
5 & Essential or strong preference \\
7 & Very strong preference \\
9 & Extreme preference \\
$2,4,6,8$ & Intermediate values when compromise is needed \\
\hline
\end{tabular}

Saaty et al. [11] presents the rank reversal phenomenon using three alternatives $\mathrm{A}, \mathrm{B}$, and $\mathrm{C}$ with respect to three criteria $\mathrm{C}_{1}, \mathrm{C}_{2}$, and $\mathrm{C}_{3}$, respectively (Table 2 ). The numbers to alternatives are assigned one at a time by using the ratings mode. However, it is also assumed that the data have been derived from consistent judgment matrices with pairwise comparisons in order to avoid any other possible effects from inconsistent measurements in the decision problem.

Table 2. Decision problem set

\begin{tabular}{|l|l|l|l|}
\hline \multirow{2}{*}{ Alternative } & \multicolumn{3}{|c|}{ Decision criteria } \\
\cline { 2 - 4 } & $\boldsymbol{C}_{\boldsymbol{I}}$ & $\boldsymbol{C}_{\mathbf{2}}$ & $\boldsymbol{C}_{\mathbf{3}}$ \\
& $(\mathbf{1} / \mathbf{3})$ & $(\mathbf{1} / \mathbf{3})$ & $(\mathbf{1 / 3})$ \\
\hline$A$ & 1 & 9 & 8 \\
$B$ & 9 & 1 & 9 \\
$C$ & 1 & 1 & 1 \\
\hline
\end{tabular}

Table 3. Adding an alternative in the distributive AHP

\begin{tabular}{|c|c|c|c|c|c|c|}
\hline \multirow[t]{2}{*}{ Addition } & \multirow[t]{2}{*}{ Alternative } & \multicolumn{3}{|c|}{ Criteria weights } & \multirow{2}{*}{$\begin{array}{l}\text { Composite } \\
\text { Weights }\end{array}$} & \multirow[t]{2}{*}{ Rank } \\
\hline & & $\begin{array}{l}C_{1} \\
(1 / 3)\end{array}$ & $\begin{array}{l}C_{2} \\
(1 / 3)\end{array}$ & $\begin{array}{l}C_{3} \\
(1 / 3)\end{array}$ & & \\
\hline & A & $1 / 11$ & $9 / 11$ & $8 / 18$ & 0.451 & 2 \\
\hline & B & $9 / 11$ & $1 / 11$ & $9 / 18$ & 0.469 & 1 \\
\hline & C & $1 / 11$ & $1 / 11$ & $1 / 18$ & 0.070 & 3 \\
\hline & A & $1 / 20$ & $9 / 12$ & $8 / 27$ & 0.356 & 1 \\
\hline & B & $9 / 20$ & $1 / 12$ & $9 / 27$ & 0.295 & 2 \\
\hline & C & $1 / 20$ & $1 / 12$ & $1 / 27$ & 0.054 & 3 \\
\hline$D=a$ copy of $B$ & D & $9 / 20$ & $1 / 12$ & 9/27 & 0.295 & 2 \\
\hline
\end{tabular}




\begin{tabular}{|l|l|l|l|l|l|l|}
\hline & A & $1 / 19$ & $9 / 12$ & $8 / 26$ & 0.361 & 1 \\
& B & $9 / 19$ & $1 / 12$ & $9 / 26$ & 0.307 & 2 \\
& C & $1 / 19$ & $1 / 12$ & $1 / 26$ & 0.055 & 4 \\
$\mathrm{D}=$ a near copy of B & D & $8 / 19$ & $1 / 12$ & $8 / 26$ & 0.276 & 3 \\
\hline
\end{tabular}

To obtain the local priorities of alternatives in the decision matrix, the original AHP [10], also known as the distributive AHP uses a principal Eigenvalue Method (EM), which requires that one adds the measurement values under each criterion, and divides each measurement by the sum of the measurements with respect to all other criteria. They assume that the three criteria have an equal weight of importance and derived a ranking for A, B and C.

According to Table 3, before $\mathrm{D}$ is added, the ranking between $\mathrm{A}$ and $\mathrm{B}$ in the original decision matrix is $\mathrm{B}>\mathrm{A}$. However, adding $\mathrm{D}$ which is a copy of $\mathrm{B}$, changes the preference of $\mathrm{A}$ over $\mathrm{B}$. The rank is reversed, with $\mathrm{A}(.356)$ preferred to $B(.295)$. Also when we introduce an alternative $D$ which is a small change of $B$ with respect to $\mathrm{C}_{1}$, identical to $C_{2}$, and a small change of $B$ with respect to $C_{3}$, we have $A=0.361 B=0.307$, and $A$ is preferred to $B$.

The following example involves three alternatives $A, B$ and $C$ with respect to two criteria $C_{1}$ and $C_{2}$ respectively. The criterion weights are $\mathrm{C}_{1}=3 / 10$ and $\mathrm{C}_{2}=7 / 10$. Table 4 shows that the ranking between $\mathrm{A}$ and $\mathrm{B}$ in the original decision matrix is $\mathrm{A}(.381)>\mathrm{B}(.379)$ before $\mathrm{C}$ is removed. However, when we remove an alternative $\mathrm{A}_{3}$, we have $\mathrm{A}$ $=0.490 \mathrm{~B}=0.510$, and now $\mathrm{B}$ is preferred to $\mathrm{A}$.

Table 4. Removing an alternative

\begin{tabular}{|l|l|l|l|l|}
\hline \multirow{2}{*}{ Alternative } & \multicolumn{2}{|l|}{ Criteria weights } & \multirow{2}{*}{ Composite } & \\
\cline { 2 - 5 } & $\begin{array}{l}\mathbf{C}_{\mathbf{1}} \\
\mathbf{( 3 / 1 0 )}\end{array}$ & $\begin{array}{l}\mathbf{C}_{\mathbf{2}} \\
\mathbf{( 7 / 1 0 )}\end{array}$ & $\begin{array}{l}\text { Reights } \\
\text { Rank }\end{array}$ \\
\hline $\mathrm{A}$ & 57 & 3 & 0.381 & 1 \\
$\mathrm{~B}$ & 33 & 4 & 0.379 & 2 \\
$\mathrm{C}$ & 10 & 3 & 0.240 & 3 \\
\hline $\mathrm{A}$ & 57 & 3 & 0.490 & 2 \\
$\mathrm{~B}$ & 33 & 4 & 0.510 & 1 \\
\hline
\end{tabular}

As is known for most multiple comparison decision making problems, in order to get rid of the dimensions of different decision attributes, normalization is necessary. Two examples of the rank reversal seem to depict that the rank reversal is presumably caused by procedural flaws of the normalization method. The alternative approach to yield the most reliable initial ranking and to preserve the ranking is proposed in next section.

\section{A proposed Least Common Multiple (LCM) approach}

Shin et al. $[13,14]$ propose an alternative approach that converts all measurement values of alternatives to the commensurate values by multiplying a least common multiple (LCM) of all column sums of criteria in the decision matrix. Before the composite weights of all alternatives are computed, a matrix, $A_{i j}{ }^{\prime}$ is multiplied by $L$, a least common multiple of all column sums of criteria, where $L=\sum_{j=1} \sum_{i=1} a_{i j}$

Now the weight vector of criteria $\left(C_{j}\right)$ is given by $C_{j}=\left[\begin{array}{lllll}c_{1} & c_{2} & c_{3} & \ldots & c_{j}\end{array}\right]^{T}$. Then, multiplying the criteria weight vector $\mathrm{C}_{j}$ by the revised value matrix $A_{i j}$ " yields the following data matrix, $X_{i}$. 


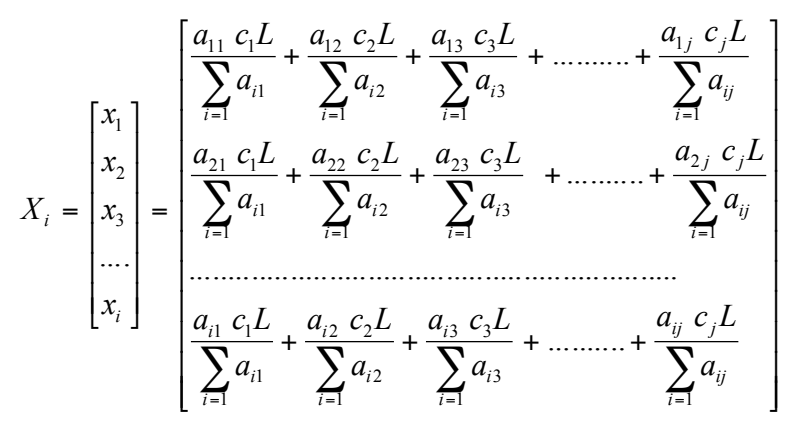

Finally, the normalized composite weights of alternatives are obtained from the following equation,

$$
X_{i}^{\prime}=\left[\begin{array}{cccc}
\frac{x_{1}}{\sum_{i=1} x_{i}} & \frac{x_{2}}{\sum_{i=1} x_{i}} & \frac{x_{3}}{\sum_{i=1} x_{i}} \ldots \ldots \ldots . . \cdots & x_{i} x_{i}
\end{array}\right]^{T}
$$

Because of the converted matrix of the unified commensurate unit, rank reversal problems in the AHP can be prevented without adjusting the weights of criteria or wondering about structural or functional dependency and independency. To verify the validity of our proposed approach, the next paragraphs present the results of LCM mode by re-examining the decision matrices used in two examples in the previous section.

Table 5 shows that the rankings in the original decision matrix are $\mathrm{B}>\mathrm{A}>\mathrm{C}$ before $\mathrm{D}$ is added. Now, the rankings are preserved as $\mathrm{B}=\mathrm{D}>\mathrm{A}>\mathrm{C}$ and $\mathrm{B}>\mathrm{A}>\mathrm{D}>\mathrm{C}$, regardless of whether a new alternative, $\mathrm{D}$ (a copy or a near copy of alternative $\mathrm{B}$ ), is added. In Table 6 , the ranking between $\mathrm{A}$ and $\mathrm{B}$ in the original decision matrix is $\mathrm{A}>\mathrm{B}$ before $\mathrm{C}$ is removed. When we remove an alternative $\mathrm{C}$, we have $\mathrm{A}=0.512 \mathrm{~B}=0.488$, and now $\mathrm{A}$ is still preferred to $\mathrm{B}$.

\begin{tabular}{|c|c|c|c|c|c|c|}
\hline \multirow{2}{*}{ Addition } & \multirow{2}{*}{ Alternative } & \multicolumn{3}{|c|}{ Criteria weights } & \multirow{2}{*}{$\begin{array}{l}\text { Composite } \\
\text { Weights }\end{array}$} & \multirow{2}{*}{ Rank } \\
\hline & & $C_{1}(1)$ & $C_{2}(1)$ & $\mathrm{C}_{3}(\mathbf{1})$ & & \\
\hline & A & $1 * 198 / 11$ & $9 * 198 / 11$ & $8 * 198 / 18$ & 0.451 & 2 \\
\hline & B & $9 * 198 / 11$ & $1 * 198 / 11$ & $9 * 198 / 18$ & 0.470 & 1 \\
\hline & $\mathrm{C}$ & $1 * 198 / 11$ & $1 * 198 / 11$ & $1 * 198 / 18$ & 0.079 & 3 \\
\hline \multirow[b]{4}{*}{$\mathrm{D}=\mathrm{a}$ copy of $\mathrm{B}$} & A & $1 * 198 / 11$ & $9 * 198 / 11$ & $8 * 198 / 18$ & 0.307 & 2 \\
\hline & B & $9 * 198 / 11$ & $1 * 198 / 11$ & $9 * 198 / 18$ & 0.320 & 1 \\
\hline & $\mathrm{C}$ & $1 * 198 / 11$ & $1 * 198 / 11$ & $1 * 198 / 18$ & 0.054 & 3 \\
\hline & $\mathrm{D}$ & $9 * 198 / 11$ & $1 * 198 / 11$ & $9 * 198 / 18$ & 0.320 & 1 \\
\hline \multirow[b]{4}{*}{$\mathrm{D}=\mathrm{a}$ near copy of $\mathrm{B}$} & A & $1 * 198 / 11$ & $9 * 198 / 11$ & $8 * 198 / 18$ & 0.318 & 2 \\
\hline & B & $9 * 198 / 11$ & $1 * 198 / 11$ & $9 * 198 / 18$ & 0.331 & 1 \\
\hline & $\mathrm{C}$ & $1 * 198 / 11$ & $1 * 198 / 11$ & $1 * 198 / 18$ & 0.056 & 4 \\
\hline & $\mathrm{D}$ & $8 * 198 / 11$ & $1 * 198 / 11$ & $8 * 198 / 18$ & 0.296 & 3 \\
\hline
\end{tabular}

Table 5. Adding an Alternative in LCM Mode Approach

Table 6. Deleting an Alternative in LCM Mode Approach 


\begin{tabular}{|c|c|c|c|c|}
\hline \multirow[b]{2}{*}{ Alternative } & \multicolumn{2}{|c|}{ Criteria weights } & \multirow[b]{2}{*}{ Composite weights } & \multirow[b]{2}{*}{ Rank } \\
\hline & $\begin{array}{l}C_{1} \\
\mathbf{L C M} \\
(3 / 10)\end{array}$ & $\begin{array}{l}\mathrm{C}_{2} \\
\mathrm{LCM} \\
(\mathbf{7} / \mathbf{1 0})\end{array}$ & & \\
\hline$\overline{\mathrm{A}}$ & $57 * 100 / 100$ & $3 * 100 / 10$ & 0.381 & 1 \\
\hline B & $33 * 100 / 100$ & $4 * 100 / 10$ & 0.379 & 2 \\
\hline $\mathrm{C}$ & $10 * 100 / 100$ & $3 * 100 / 10$ & 0.240 & 3 \\
\hline$\overline{\mathrm{A}}$ & $57 * 100 / 100$ & $3 * 100 / 10$ & 0.501 & 1 \\
\hline B & $33 * 100 / 100$ & $4 * 100 / 10$ & 0.499 & 2 \\
\hline
\end{tabular}

\section{RANK REVERSALS IN OTHER MCDM TECHNIQUES}

There are a wide range of MCDM problem solution techniques, varying in complexity and possible solutions. Each method has its own strength, weaknesses and possibilities to be applied. Among them, it is obvious that most popular MCDM approaches, such as Borda-Kendall, TOPSIS and the SAW method, also suffer from rank reversal. In this section we illustrate that the rank reversals occur in these popular MCDM approaches.

\section{Borda-Kendall method}

Multiple criteria decisions are also commonly used to formulate consensus ranking problems. Consensus ranking has a strong interdisciplinary nature and is considered in organizational sciences, marketing research, and management science. The Borda-Kendall (BK) method [5] is the most widely used tool in determining a consensus ranking because of its computational simplicity. It uses a weighted ordinal ranking model in which each of a set of $n$ alternatives was given an ordinal rank on a set of criteria [3].

Suppose there are $m$ voters who vote on $n$ candidates. Each candidate will receive some votes at different ranking places. The BK method assigns the first ranking place a mark of one, the second ranking place a mark of two, and so on. The total score $\left(Z_{i}\right)$ each candidate receives can be computed by aggregating the results from the simple equation, $Z_{i}=\sum_{j=1}^{n} j v_{i j}$, the votes that each candidate receives $j$ th ranking place. The best candidate will be the one with the least total score. Table 6 shows a voting problem in which 60 voters vote on three political candidates. After the voting is completed, B is the best candidate, followed by candidates A and C. Clearly, candidate C is the most undesirable candidate and can be dropped out of further votes system.

Suppose candidate $\mathrm{C}$ is dropped and the 60 voters' preferences on the candidates $\mathrm{A}$ and $\mathrm{B}$ remain unchanged. Then, the result shows that candidate B is no longer a better candidate than A. The ranking between A and B is reversed. Similarly, if B is dropped for whatever reason, the ranking between remaining candidates $\mathrm{A}$ and $\mathrm{C}$ is reversed. Table 7 also shows the proposed LCM method preserves the original rankings in all cases.

Table 7. Voting among three political candidates by 60 voters

\begin{tabular}{|c|c|c|c|c|c|c|c|c|c|c|}
\hline \multirow[t]{2}{*}{ Alternatives } & \multicolumn{5}{|c|}{ Number of votes } & \multirow{2}{*}{$\begin{array}{l}\text { Total } \\
\text { Score }\end{array}$} & \multirow{2}{*}{$\begin{array}{l}\text { BK } \\
\text { Average }\end{array}$} & \multirow{2}{*}{$\begin{array}{l}\text { BK } \\
\text { Rank }\end{array}$} & \multirow{2}{*}{$\begin{array}{l}\text { LCM } \\
\text { Weights }\end{array}$} & \multirow{2}{*}{$\begin{array}{l}\text { LCM } \\
\text { Rank }\end{array}$} \\
\hline & 23 & 17 & 2 & 10 & 8 & & & & & \\
\hline A & 1 & 3 & 2 & 2 & 3 & 122 & 2.03 & $\mathrm{~B}>\mathrm{A}>\mathrm{C}$ & 0.339 & $\mathrm{~B}>\mathrm{A}>\mathrm{C}$ \\
\hline B & 2 & 1 & 1 & 3 & 2 & 111 & 1.85 & & 0.308 & \\
\hline $\mathrm{C}$ & 3 & 2 & 3 & 1 & 1 & 127 & 2.12 & & 0.353 & \\
\hline
\end{tabular}




\begin{tabular}{lllllllllll}
\hline $\mathrm{A}$ & 1 & 2 & 2 & 1 & 2 & 87 & 1.45 & $* \mathrm{~A}>\mathrm{B}$ & 0.524 & $\mathrm{~B}>\mathrm{A}$ \\
$\mathrm{B}$ & 2 & 1 & 1 & 2 & 1 & 93 & 1.55 & & 0.476 & \\
\hline $\mathrm{A}$ & 1 & 2 & 1 & 2 & 2 & 95 & 1.58 & $* \mathrm{C}>\mathrm{A}$ & 0.490 & $\mathrm{~A}>\mathrm{C}$ \\
$\mathrm{C}$ & 2 & 1 & 2 & 1 & 1 & 85 & 1.42 & & 0.510 & \\
\hline
\end{tabular}

\section{Simple Additive Weighting (SAW) method}

Simple Additive Weighting (SAW), which is also known as a weighted linear scoring method is simple and the most frequently used multiple attribute decision making (MADM) tool [6]. The SAW is used for a MADM problem with $n$ alternatives and $m$ decision attributes (criteria). Each alternative is evaluated with respect to the $m$ attributes. The evaluation score is normalized by the following equation (4) to eliminate the dimensional units of the attributes.

$$
A_{i j}=\left(a_{i j}-a_{j}^{\min }\right) \div\left(a_{j}^{\max }-a_{n}^{\min }\right), \quad i=1, \ldots, n ; j=1, \ldots, m
$$

The overall assessment value of each alternative is computed by multiplying the evaluation value given to the alternative of that attribute with the weights of relative importance directly assigned by decision maker followed by summing of the products for all criteria. The greater the overall priority value, the better the alternative.

It is easily noticed that the SAW method is also subject to the rank reversal problem when an alternative is added or dropped. In Table 8, with SAW method, when a new alternative $\mathrm{E}$ is added, the ranking between alternatives $\mathrm{B}$ and $\mathrm{D}$ is reversed. When an alternative $\mathrm{D}$ is dropped out from the original set of alternatives, the ranking between $\mathrm{B}$ and $\mathrm{C}$ is reversed with the alternative $\mathrm{B}$ becoming the best alternative. However, it can be observed that the proposed LCM method preserves the original rankings in both cases.

Table 8. Decision matrix for SAW method

\begin{tabular}{|c|c|c|c|c|c|c|c|c|}
\hline \multirow[t]{2}{*}{ Alternatives } & \multicolumn{4}{|c|}{ Criteria eights } & \multirow[b]{2}{*}{$\begin{array}{l}\text { SAW } \\
\text { Weights }\end{array}$} & \multirow[b]{2}{*}{$\begin{array}{l}\text { SAW } \\
\text { Rank } \\
\end{array}$} & \multirow[b]{2}{*}{$\begin{array}{l}\text { LCM } \\
\text { Weights }\end{array}$} & \multirow[b]{2}{*}{$\begin{array}{l}\text { LCM } \\
\text { Rank } \\
\end{array}$} \\
\hline & $\begin{array}{l}\mathrm{C} 1 \\
(1 / 6)\end{array}$ & $\begin{array}{l}\mathrm{C} 2 \\
(1 / 3)\end{array}$ & $\begin{array}{l}\mathrm{C} 3 \\
(1 / 3) \\
\end{array}$ & $\begin{array}{l}\mathrm{C} 4 \\
(1 / 6)\end{array}$ & & & & \\
\hline A & 36 & 42 & 43 & 70 & 0.2333 & $\mathrm{C}>\mathrm{B}>\mathrm{D}>\mathrm{A}$ & 0.2456 & $\mathrm{C}>\mathrm{B}>\mathrm{D}>\mathrm{A}$ \\
\hline B & 25 & 50 & 45 & 80 & 0.4980 & & 0.2531 & \\
\hline $\mathrm{C}$ & 28 & 45 & 50 & 75 & 0.5833 & & 0.2546 & \\
\hline $\mathrm{D}$ & 24 & 40 & 47 & 100 & 0.3571 & & 0.2467 & \\
\hline A & 36 & 42 & 43 & 70 & 0.3667 & $*^{*} \mathrm{C}>\mathrm{D}>\mathrm{B}>\mathrm{A}>\mathrm{E}$ & 0.2008 & $\mathrm{C}>\mathrm{B}>\mathrm{D}>\mathrm{A}>\mathrm{E}$ \\
\hline B & 25 & 50 & 45 & 80 & 0.4980 & & 0.2070 & \\
\hline $\mathrm{C}$ & 28 & 45 & 50 & 75 & 0.6667 & & 0.2082 & \\
\hline $\mathrm{D}$ & 24 & 40 & 47 & 100 & 0.5238 & & 0.2017 & \\
\hline $\mathrm{E}$ (new) & 30 & 30 & 45 & 80 & 0.2341 & & 0.1822 & \\
\hline A & 36 & 42 & 43 & 70 & 0.1667 & $* \mathrm{~B}>\mathrm{C}>\mathrm{A}$ & 0.3260 & $\mathrm{C}>\mathrm{B}>\mathrm{A}$ \\
\hline B & 25 & 50 & 45 & 80 & 0.5952 & & 0.3360 & \\
\hline $\mathrm{C}$ & 28 & 45 & 50 & 75 & 0.5871 & & 0.3380 & \\
\hline
\end{tabular}

Technique for Order Preference by Similarity to Ideal Solution (TOPSIS) method 
The TOPSIS method is a goal based approach for finding the alternative that is closest to the ideal solution [6]. The general TOPSIS process with 5 steps is listed as follows: From a basic structure of decision problem with $n$ alternatives and $m$ decision attributes, normalized attribute values $\left(r_{i j}\right)$ are computed by $r_{i j}=a_{i j} \sqrt{\sum_{j=1}^{n}\left(a_{i j}\right)^{2}}$. The weighted normalized attribute values $\left(v_{i j}\right)$ are computed by $v_{i j}=w_{j} r_{i j}$. Then the positive ideal solution $\left(\max v_{i j} \mid j \epsilon\right.$ $\mathrm{J})$ and the negative ideal solution $\left(\min v_{i j} \mid j \in \mathrm{J}\right)$ are determined by the decision maker. Next, calculate the separation measure $\left(s_{i}^{*}\right.$, Euclidean distance) of each alternative from the positive ideal one with $S_{i}^{*}=\sqrt{\sum_{j=1}^{n}\left(v_{i j}-v_{j}^{*}\right)^{2}}$, and the separation measure $\left(S_{i}^{-}\right)$of each alternative from the negative ideal one with $S_{i}^{-}=\sqrt{\sum_{j=1}^{n}\left(v_{i j}-v_{j}^{-}\right)^{2}}$. Finally, the TOPSIS weights (relative closeness) of alternative $A_{i}$ to the ideal solution are computed with $C_{i}=S_{i}^{-} /\left(S_{i}^{*}-S_{i}^{-}\right)$. The larger the $S_{i}^{*}$ value, the better the performance of the alternatives.

Consider the decision matrix used with SAW method in Table 8 again. In Table 9, the result of TOPSIS method indicates that this method is also not free from the rank reversal when an alternative is introduced or removed. When a new alternative $\mathrm{E}$ is added to the original set of the four alternatives, the rankings between $\mathrm{B}$ and $\mathrm{C}$ as well as $\mathrm{A}$ and $\mathrm{D}$ are both reversed. When $\mathrm{D}$ is removed from the original decision matrix, the ranking between $\mathrm{B}$ and $\mathrm{C}$ is reversed.

Additionally, regarding the ranking of the original set of the four alternatives, the TOPSIS method yields an alternative B as the best, which is different from that computed by the SAW method (an alternative C is the best). However, the proposed LCM method provides a consistent ranking of an original set of alternatives and preserves the original rankings where an alternative is added or dropped out.

Table 9. Decision matrix of four alternatives with respect to four attributes

\begin{tabular}{|c|c|c|c|c|c|c|c|c|}
\hline \multirow[b]{2}{*}{ Alternatives } & \multicolumn{4}{|c|}{ Criteria weights } & \multirow[b]{2}{*}{$\begin{array}{l}\text { TOPSIS } \\
\text { Weights }\end{array}$} & \multirow[b]{2}{*}{$\begin{array}{l}\text { TOPSIS } \\
\text { Rank }\end{array}$} & \multirow[b]{2}{*}{$\begin{array}{l}\text { LCM } \\
\text { Weights } \\
\end{array}$} & \multirow[b]{2}{*}{$\begin{array}{l}\text { LCM } \\
\text { Rank }\end{array}$} \\
\hline & $\begin{array}{l}\text { C1 } \\
(1 / 6)\end{array}$ & $\begin{array}{l}\mathrm{C} 2 \\
(1 / 3)\end{array}$ & $\begin{array}{l}\text { C3 } \\
(1 / 3)\end{array}$ & $\begin{array}{l}\mathrm{C} 4 \\
(1 / 6)\end{array}$ & & & & \\
\hline A & 0.105 & 0.158 & 0.155 & 0.071 & 0.4184 & $\mathrm{~B}>\mathrm{C}>\mathrm{A}>\mathrm{D}$ & 0.2456 & $\mathrm{C}>\mathrm{B}>\mathrm{D}>\mathrm{A}$ \\
\hline B & 0.073 & 0.188 & 0.162 & 0.081 & 0.4858 & & 0.2531 & \\
\hline $\mathrm{C}$ & 0.081 & 0.169 & 0.180 & 0.076 & 0.4634 & & 0.2546 & \\
\hline $\mathrm{D}$ & 0.070 & 0.150 & 0.169 & 0.102 & 0.3915 & & 0.2467 & \\
\hline A & 0.093 & 0.141 & 0.142 & 0.064 & 0.4257 & ${ }^{*} \mathrm{C}>\mathrm{B}>\mathrm{D}>\mathrm{A}>\mathrm{E}$ & 0.2008 & $\mathrm{C}>\mathrm{B}>\mathrm{D}>\mathrm{A}>\mathrm{E}$ \\
\hline B & 0.064 & 0.167 & 0.149 & 0.073 & 0.5063 & & 0.2070 & \\
\hline $\mathrm{C}$ & 0.072 & 0.151 & 0.165 & 0.068 & 0.5250 & & 0.2082 & \\
\hline $\mathrm{D}$ & 0.062 & 0.134 & 0.155 & 0.091 & 0.4345 & & 0.2017 & \\
\hline$E$ (new) & 0.077 & 0.151 & 0.132 & 0.073 & 0.3577 & & 0.1822 & \\
\hline A & 0.115 & 0.177 & 0.180 & 0.090 & 0.4319 & $* \mathrm{C}>\mathrm{B}>\mathrm{A}$ & 0.3260 & $\mathrm{C}>\mathrm{B}>\mathrm{A}$ \\
\hline B & 0.080 & 0.210 & 0.188 & 0.102 & 0.4742 & & 0.3360 & \\
\hline $\mathrm{C}$ & 0.090 & 0.189 & 0.209 & 0.096 & 0.5007 & & 0.3380 & \\
\hline
\end{tabular}

\section{CONCLUSIONS}

There is no doubt that the AHP is a powerful method in multi-criteria decision making area. It is assumed that the AHP will continue to be useful for many future cases as it has been in the past. Despite this widespread usage, the 


\section{Issues in Information Systems}

Volume 14, Issue 1, pp.358-365, 2013

AHP still suffers from some theoretical disputes. Rank reversals are also found in many other well-known MCDM methods. Many studies argue that the rank reversal phenomenon is unpreventable when any MCDM method is applied. Some show that this phenomenon seems to be an inherited problem when a decision maker deals with criteria which are measured on different units.

The available wide range of MCDM problem solution techniques, varying in complexity and possible solutions, confuses potential decision makers. Each method has its own strengths, weaknesses and possibilities to be applied. This can cause inconsistent ranking problem caused by different MCDM methods. As seen in the section of TOPSIS method, a primary criticism of MCDM methods is that due to the differences among different techniques, inconsistent results are obtained when applied to the same decision problem.

It is important that a good MCDM method must not yield the ranking reversals when an alternative is added and removed. Even though the proposed method does not suffer from those problems, it is more important that additional research in decision analysis is necessary to produce the reliable rankings one may trust.

\section{REFERENCES}

1. Barzilai, J. \& Golany, B. (1994). AHP rank reversal, normalization and aggregation rules, INFOR, 32(2), 57-63. 2. Belton, V. \& Gear, T. (1983). On a shortcoming of Saaty's method of analytic hierarchies. Omega, 11 (3), 228230.

3. Cook, W.D., Kress, M., \& Seiford, L.M. (1997) A general framework for distance-based consensus in ordinal ranking models, European Journal of Operational Research 96, 392-397.

4. Dyer, J. \& Wendell, R. (1985). A critique of the Analytic Hierarchy Process. Technical Report, 84/85, 4-24. Department of Management. The University of Texas at Austin.

5. Hwang, C.L., \& Lin, M.J. (1987). Group decision making under multiple criteria. Lecture Notes in Economics and Mathematical Systems, 281, Springer, Berlin.

6. Hwang, C.L., \& Yoon, M. M (1981). Multiple Attribute Decision Making: Methods and Applications, SpringerVerlag, Berlin.

7. Kendall, M. (1962). Rank correction Methods, $3^{\text {rd }}$ Ed. Hafner, New York.

8. Lootsma, F. (1999). Multi-criteria decision analysis via ratio and difference judgment. Kluwer Academic Publishers: Dordrecht.

9. MacCrimon, K.R. (1968). Decision making among multiple attribute alternatives: A survey and consolidated approach. RAND Memorandum, RM-4823-ARPA. The Rand Corporation, Santa Monica, CA.

10. Saaty, T.L. (1980). The analytic hierarchy process. McGraw-Hill International: New York.

11. Saaty, T.L. \& Sagir, M. (2009). An essay on rank preservation and reversal. Mathematical and Computer Modelling, 49, 1230-1243.

12. Schoner, B., Wedley, W.C., \& Choo, E.U. (1993). A unified approach to AHP with linking pins. European Journal of Operational Research, 64, 384-392.

13. Shin, Y.B. \& Lee, S.H. (2012). Note on an approach to preventing rank reversals with addition or deletion of an Analytic Hierarchy Process. Journal of Education Review 3(1), 66-72.

14. Shin, Y.B. \& Lee, S.H. (2013). Remarks on Rankings by Different Methods in AHP. International Journal of Business Disciplines. (forthcoming). 